Sciendo

\title{
Visual Experience and Demonstrative Thought
}

\author{
Thomas Raleigh \\ Becario del Programa de Becas Posdoctorales de la UNAM, \\ Instituto de Investigaciones Filosóficas
}

Disputatio Vol. 4, No. 30

May 2011

DOI: $10.2478 /$ disp-2011-0005

ISSN: 0873-626X

(C) 2011 Raleigh. Creative Commons Attribution-NonCommercial-NoDerivs 3.0 License 


\title{
Visual Experience and Demonstrative Thought
}

\author{
Thomas Raleigh \\ Becario del Programa de Becas Posdoctorales de la UNAM, \\ Instituto de Investigaciones Filosóficas
}

\begin{abstract}
I raise a problem for common-factor theories of experience concerning the demonstrative thoughts we form on the basis of experience. Building on an insight of Paul Snowdon 1992, I argue that in order to demonstratively refer to an item via conscious awareness of a distinct intermediary the subject must have some understanding that she is aware of a distinct intermediary. This becomes an issue for common-factor theories insofar as it is also widely agreed that the general, pre-philosophical or 'naïve' view of experience does not accept that in normal perceptual cases one is consciously aware of non-environmental (inner, mental) features. I argue then that the standard common-factor view of experience should be committed to attributing quite widespread referential errors or failures amongst the general, nonphilosophical populace - which seems an unattractively radical commitment. After clarifying the various assumptions I am making about experience and demonstrative thoughts, I consider a number of possible responses on behalf of the common-factor theorist. I finish by arguing that my argument should apply to any common-factor theory, not just avowedly 'indirect' theories.
\end{abstract}

\section{Keywords}

Visual Experience, Demonstrative Thought, Common-factor, Intentionalism, Paul Snowdon.

\section{Overview}

There is an ancient debate as to whether what visual consciousness provides - the 'visual field' - is, at least sometimes, access to the mind-independent environment itself, or to some sort of features that can be common to perception and hallucinations/dreams. This latter,

Disputatio, Vol. IV, No. 30, May 2011 
orthodox view, is held by various theories as to the metaphysics of experience - sense-data theories, adverbial theories and most intentional or representational theories, are all common-factor theories ${ }^{1}$. I want to raise an issue for common-factor (CF) theories concerning the account they yield of demonstrative thoughts formed on the basis of experience.

According to what I will henceforth call the natural story, when we selectively attend to - or 'single-out' - some feature or element in our visual field, we can thereby form a demonstrative thought about it. Sometimes one can look at an item and attend to it in one's visual field as part of thinking about some other, distinct item. For example: S can attend to a waxwork sculpture of Barack Obama in her visual field and think 'That is the first black president of the Harvard Law Review'. S's thought here can refer to Obama rather than to the sculpture. However, it seems that in such a case $\mathrm{S}$ needs to have some understanding that the 'proximal' item in her visual field is distinct from, but related to, the other 'distal' item. If $\mathrm{S}$ really would not acknowledge that she is looking at a model/representation of Obama rather than the real Obama, then it seems that her demonstrative thought should count as false. She has mistakenly demonstrated and so referred to something other than the first black president of the Harvard Law Review.

Why should this be a problem for common-factor theories? Well, it is commonly accepted that such theories are revisionary with respect to everyday, non-philosophical beliefs. In other words, nonphilosophers would not in general acknowledge as true the claim that the elements comprising the visual field are distinct from (though related to) any environmental features. (Hence the label: 'naïve realism'.) So they would be regularly mistaking a non-environmental feature for an environmental feature. But given the above line of reasoning, such a mistake should mean that the non-philosophical laity would be quite systematically failing to refer to features in their environment when they form demonstrative thoughts via experience - and so quite systematically forming false demonstrative thoughts via experience (or perhaps failing to form thoughts that refer at all). This

\footnotetext{
1 Some versions of intentionalism, e.g. Tye 2009, allow for objectdependent content in perceptual cases, with 'gappy' content in the case of hallucinations, and so are not so clearly 'common-factor' theories.
} 
seems like an unattractively radical consequence for a theory to have, though it is not necessarily a decisive flaw.

The plan for this paper is as follows:

(1) First I'll outline some assumptions contained in what I've called the 'natural story' about demonstrative reference via experience.

(2) Secondly I'll flesh out a little more the central claim, which I draw from Paul Snowdon 1992, that experience of a distinct intermediary can only be a means for demonstratively referring to some other item if the subject understands that it is the intermediary that they are experiencing.

(3) Thirdly, I'll consider some possible complicated cases, which might be thought to be counter-examples to Snowdon's point, where there are competing means or channels that might be determining the reference of a demonstrative thought.

(4) Fourthly, I'll consider some possible responses by CF theorists.

(5) Finally, I'll make a few remarks about the distinction between 'direct' and 'indirect' awareness and about intentionalist theories of experience.

\section{Some Assumptions}

It has seemed plausible to many philosophers that when we perceive an item (object or feature) we are able to think about it in a certain way. Perceptual experience allows for demonstrative thought. Demonstrative thought here contrasts with descriptive thought. A descriptive thought about $\mathrm{O}$ involves thinking of $\mathrm{O}$ via a descriptive or conceptual mode of presentation, whereas in a demonstrative thought one refers to $\mathrm{O}$ without any such descriptive/conceptual mode of presentation. Here is Robin Jeshion articulating this distinction:

'I can think that a particular rose is lovely by thinking "the tallest yellow rose in the garden is lovely". My thought is about that particular rose because it satisfies, 'fits', the descriptive condition the tallest yellow rose in the garden. Alternatively, I can think of these individuals in a way that does not depend essentially on my mode of conceptualising them. I can visually attend to the rose itself and think that is lovely, where "that", as it functions in my thought, refers deictically to the object I attend to - that very rose.' (Jeshion 2010: 1) 
I will not attempt to defend or motivate this widely accepted distinction between demonstrative and descriptive thoughts - I will simply assume that there is such a distinction. Jeshion's passage contains what I take to be a very natural and plausible story: by selectively attending to some element in one's visual field, one is able to form a demonstrative thought about it and to demonstratively refer to it. On this story, the act of directing one's (cognitive) attention is (partially) determining the reference of the demonstrative component of one's thought. (I will generally speak of 'singling out' for this mental act of focusing/directing cognitive attention at one particular element in one's visual field.)

In his Reference and Consciousness, John Campbell 2002 argued for the thesis that:

- Conscious experience of $\mathrm{O}$ is necessary for demonstrative reference to $\mathrm{O}$.

Against this thesis it could be claimed that, at least in principle, nonconscious perception of $\mathrm{O}$ could allow for demonstrative reference to $\mathrm{O}$. Or indeed it might be claimed that perception of $\mathrm{O}$, whether conscious or not, is unnecessary for demonstrative thought about O. I will not attempt to defend or motivate this thesis ${ }^{2}$. The natural story about experience and demonstratives requires only a weaker thesis:

- Normal humans can, and often do in fact, make demonstrative reference to $\mathrm{O}$ via their conscious experience of $\mathrm{O}$.

In other words, whether or not it is the only way to demonstratively refer to $\mathrm{O}$, I assume that a subject's conscious experience of $\mathrm{O}$ can play a role in allowing the subject to demonstratively refer to $O$.

In order to be able to selectively attend to an element in one's visual field (i.e. to 'single it out') and so to 'tag' it with a demonstrative 'that...', one need as yet know nothing at all about the element. One could simply wonder: 'What's that?' without yet having formed any beliefs about the item one sees and attends to. Perhaps one is always in a position to form some true belief about an element in one's visual experience -i.e. I don't rule out that some form of infallibility thesis

\footnotetext{
${ }^{2}$ Smithies 2009 also argues in favour of this thesis, though on somewhat different grounds to Campbell.
} 
is true. But attending to some aspect of one's experience is surely explanatorily prior to forming a belief about it; one does not need any belief about the element in order to attentively single the element out. And perhaps one will always know something trivial, such as: this is the item I am currently visually aware of. But such knowledge is not explanatory of the successful demonstrative reference - we can imagine a cognitively unsophisticated creature, which lacks any concept of visual experience, yet which still has the capacity for simple demonstrative reference to the items it sees.

These all strike me as very plausible and natural claims and so are fairly minimal assumptions to have made - though, no doubt, there might be ways to challenge them.

Now, the term 'visual field' is ambiguous between the portion of physical environment that lies within a subject's visual range, and the subject's visual experience of that environment from a particular perspective - which, according to a common-factor theorist at least, does not constitutively involve the environmental features. But this ambiguity suits our purpose here, as we need a term that is neutral between relational and common-factor ('direct' and 'indirect') theories of perceptual experience. As I am using it in this paper then, the 'visual field' consists of whatever it is that visual consciousness delivers or makes available for the subject. So I am allowing that environmental features and/or mental/inner features might be elements within the visual field.

As well as the traditional metaphysical debate about the nature of the visual field, there is a further question concerning what might be called the structure or articulation of the visual field. Imogen Dickie 2010 argues against the idea, which she labels the 'Old Empiricist View', that 'perception delivers only a shifting mosaic of features, which you will call "colour (or texture, or shape) patches" or "sensedata" depending on whether you are prepared to allow that they exist

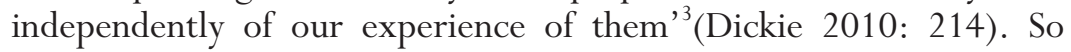

3 Actually, the term 'sense-data' was used by G. E. Moore to mean mind-independent but non-environmental features, and by Bermúdez 2000 to mean mind-independent but non-objectual environmental features (surfaces). But this is just terminology. 
orthogonal to the traditional metaphysical debate ${ }^{4}$ there is also the following question:

Whether perceptual experience provides 'an array of features laid out around us and developing over time' (Dickie 2010: 214), or whether it delivers a visual field already divided into 'units' or 'visual objects'?

Dickie points to empirical results ${ }^{5}$ which suggest the latter answer; the visual field normally comes pre-divided into 'visual objects', units which have such characteristics as spatio-temporal continuity and moving/acting as a whole, not as a mosaic of transient, shifting quality patches. (By pre-divided, Dickie means the 'processing' involved is sub-personal, pre-attentive and pre-conceptual.) These strike me as fascinating results, which are entirely in line with the natural story. But I don't need to take any position on the structure/articulation of the visual field for the purposes of this paper.

\section{Snowdon's Distinction}

Let's now turn to considering the sort of everyday case that would intuitively count as an instance of indirect awareness - that is, cases in which one might be able to 'see' one environmental item in virtue of really seeing some other environmental item. E.g. I see O's shadow, but I do not see $\mathrm{O}$ itself. Or, I see a photograph of $\mathrm{O}$ but I do not see $\mathrm{O}$ itself. These are cases in which I clearly have visual awareness of some item, $\mathrm{M}$, which is distinct from $\mathrm{O}$. (Of course there are also all sorts of difficult, unclear cases - I discuss these below in section 5.) Here the following seems quite obvious: if $I$ have no idea that $M$ bears any sort of relationship to $\mathrm{O}$, then when I mentally single out $\mathrm{M}$ in my visual field and think 'What's that?', or think 'That is F', my demonstrative refers to $\mathrm{M}$ and not O. E.g. I see (what is in fact) the

\footnotetext{
${ }^{4}$ E.g. Bermúdez 2000 argues that the visual field is constituted by mindindependent, environmental features but is not segmented/articulated into objects. Bermúdez claims that we directly experience environmental sensedata, i.e. external/mind-independent quality patches or 'surfaces' that are not standard physical objects.

${ }^{5}$ Dickie recommends, in her second footnote, Pylyshyn 2003, 2007 for a survey of this evidence. See also Campbell 2006 and the empirical work cited therein.
} 
shadow of a rabbit and think 'What's that?', or think 'That is moving quickly'. If I have no grasp or understanding whatsoever that the thing I see is related somehow to the rabbit, but distinct from the rabbit, then there is no way that my demonstrative thought can be referring to the rabbit. I must have referred to the shadow.

Of course, as soon as I have some grasp or understanding of the fact that $\mathrm{M}$ and $\mathrm{O}$ are distinct (but related) items, then I might single out $\mathrm{M}$ in my visual field whilst my thought refers to O. So long as I minimally realise that what I'm looking at is not literally the rabbit, but some distinct thing related to it, then I could, for example, mentally single out the shadow in my visual field whilst my thought refers to the rabbit. E.g. given such understanding ${ }^{6}$, my thought 'That is a rabbit' would be true.

Now let's consider a case in which I mistake M, the item I see and attentively single out, for O. E.g. I see a brilliantly life-like trompe l'oeil picture of my rabbit that fools me - I wrongly believe that the thing I'm looking at literally is my rabbit. I fail to understand that the item I see is an entity distinct from my rabbit - I would not acknowledge that there is a picture before my eyes. And now, whilst singlingout the picture in my visual field, I think: 'That is my rabbit'. What does my demonstrative thought refer to here?

I think it is pretty clear that this thought must count as false, the demonstrative having picked out a picture rather than my rabbit. At the very least we can say that:

\footnotetext{
${ }^{6}$ When I say that a subject needs some grasp or understanding of the indirect nature of their situation, I do not mean that they must explicitly think of it at the time of making their demonstrative judgement. I only mean that they would have acknowledged, if asked, that they were really aware of something distinct from O. (Again, I follow Snowdon 1992 here). E.g. whilst watching a film I can become "immersed" in the action so that I lose any explicit, occurent awareness that I am looking at an image on a flat screen. I might then think: 'That is Bruce Willis'. My thought here does still successfully refer to the real Bruce Willis so long as I would acknowledge, if asked, the truth of some such claim as: 'That is really an image of Bruce Willis'. I don't need to consciously endorse such a claim when I think my original demonstrative thought. But if I really would not have acknowledged this fact, had I been asked, then I am in trouble - for I must believe that Bruce Willis is literally located inside my TV. I would be mistaking a flat, coloured image for a real human being.
} 
If my demonstrative thought has its reference fixed by my attentive singling-out act, then I have referred to $\mathrm{M}$ (the picture), not $\mathrm{O}$ (the rabbit).

So my thought would be false, but other thoughts might, fortuitously, have been true - e.g. if I had thought 'That is white' where picture and rabbit are both white. The point is that when I am mistaken about which entity it is that's being attentively selected within the array, then a demonstrative based on this singling-out will not refer as I expect it to.

Snowdon 1992 suggests that the distinction between direct and indirect awareness can be elucidated on this basis. When $\mathrm{S}$ has direct visual awareness of $\mathrm{O}, \mathrm{S}$ does not need any particular knowledge or belief about $\mathrm{O}$ in order to be able to demonstratively refer to $\mathrm{O}$ (via a visual singling-out act). But when $\mathrm{S}$ has indirect visual awareness of $\mathrm{O}$, via visual awareness of some intermediary $\mathrm{M}, \mathrm{S}$ is only able to demonstratively refer to $\mathrm{O}$ (via a visual singling-out) if $\mathrm{S}$ has some grasp that what she is singling out is something distinct from $\mathrm{O}$ and bears some sort of linking relation to O. Snowdon puts this distinction in terms of "dependent" and "non-dependent" demonstrative reference:

SNOWDON'S Distinction: Indirect awareness of O allows only for dependent demonstrative reference to $\mathrm{O}$ - the success of which depends on the subject grasping something about $\mathrm{O}$ (its distinctness from $\mathrm{M}$ ).

Direct awareness of $\mathrm{O}$, in contrast, allows for non-dependent demonstrative reference - for the success of the demonstrative referring to $\mathrm{O}$ does not depend on anything other than the awareness itself (and the subject's minimal ability to selectively attend to elements within this awareness and 'tag' them with a demonstrative 'that...' thought).

Once we have allowed a distinction between direct and indirect visual awareness, it seems very hard to deny that Snowdon's distinction will apply to demonstrative thoughts whose reference is fixed via visual awareness. The very idea of indirect awareness must surely involve two distinct items: the subject has indirect awareness of one in virtue of having direct awareness of the other. And so it seems clear that: if reference is being fixed via the visual singling-out act, and if you are mistaken about which item it is you are singling out, then a demonstrative that refers via this singling out will not refer to the item you take yourself to be referring to. For your demonstrative to 
successfully refer to one item $(\mathrm{O})$, whilst singling out another distinct item $(\mathrm{M})$, you must understand which item is which (and that the two are connected in some way) - otherwise you will simply be mistaken as to what it is you are singling out and so what your demonstrative refers to. Indirect awareness of $\mathrm{O}$ then is a sort of awareness that can facilitate demonstrative reference to $\mathrm{O}$ only given some understanding about what one is directly aware of and singling out. Direct awareness of $\mathrm{O}$, in contrast, allows one to demonstrate $\mathrm{O}$ in thought without any such understanding - it requires only that one can mentally select a portion of one's visual field and 'tag' it in thought with a 'That...'.

\section{Some Complications}

I want to turn now to considering some possible cases where it is unclear whether the singling-out act does fix the reference of a demonstrative thought. Such cases might be thought to be counterexamples to the Snowdon point - for if the singling-out act is not fixing reference, then mistakenly singling out the wrong item, M, need not prevent reference to another item, O. My simple strategy will basically be to put these complicated cases to one side. I only need to show that there are at least some cases, common enough, in which reference is fixed via visual experience and singling-out. In these cases Snowdon's point should apply and so the issue for CF theorists will arise. I do not need to adjudicate what, if anything, determines the reference for all instances of demonstrative thought.

In cases where the subject mistakes $\mathrm{M}$ for $\mathrm{O}$, one might worry whether the reference of the demonstrative is actually fixed by the singling-out act. One might think that if I am mistaking $\mathrm{M}$ for $O$, then I'm bound to have an intention to refer to $O$. Now I will also presumably have an intention to refer to the item I have singled-out. But someone might try to argue that it is the former intention that takes precedence - i.e. the intention to refer to $\mathrm{O}$ is what matters to fixing the reference; the singling-out act (or the intention to refer via such an act) is just an idle accompaniment.

The first thing to say in response is that this would no longer be a case of demonstrative thought. If I have already formed an intention to refer to $\mathrm{O}$ when I think 'that is F', and it is this intention that is determining the reference of my thought, then I will be thinking about $\mathrm{O}$ via some pre-existent concept, or 'file', I have for $\mathrm{O}$. This 
would not be a demonstrative thought. I can allow that there can be cases of this kind. I just need to show that there are also cases of genuinely demonstrative thought, in which the singling-out act, or perhaps the intention to refer via the singling-out act, is a determinant of reference.

And there surely will be cases in which the act of singling-out $M$ fixes the reference of the thought despite an intention to refer to $\mathrm{O}$. Recall the case in which I am mistaking a sculpture of Obama for Obama himself and I think 'That is the first black president of the Harvard Law Review.' Suppose now that the real Obama enters stage-left ${ }^{7}$, so that I come to realise my mistake - I now grasp that the item I originally singled out in my visual field was not Obama. I might now react in one of two ways:

I might say: 'Oops, so my previous thought was wrong: that's the President, not this' - i.e. the reference of my previous thought was fixed by the attentional singling-out act rather than any intention to refer to Obama.

Or I might try to maintain that: 'My previous thought was correct; I was thinking about Obama being the first black president of the Harvard Law Review, though I was mistaken about the item I happened to be attending to in my visual field.' - i.e. the reference of my previous thought was fixed by my intention to refer to an item via a pre-existent/non-demonstrative concept rather than the singling-out act.

We must allow for the possibility that a subject reacts in the former way. Such a mistake would not even be possible if an intention to refer to $\mathrm{O}$ always determined reference. Moreover, if, as surely sometimes happens, the subject has formed a genuinely demonstrative

${ }^{7}$ Digression: Dean 1946 suggests that an actor's entrance is less likely to be noticed from stage-right than from stage-left. There is a wealth of interesting evidence that there is 'over-attention' to the left side of space, sometimes termed 'pseudo-neglect', perhaps as a result of the right hemisphere's specialisation for spatial processing. E.g. there is a tendency to bisect lines to the left of centre (Bowers \& Heilman 1980), and to bump into objects on our right (Turnbull \& McGeorge 1998). Also, paintings are more likely to be given titles referring to left-side objects (Nelson \& MacDonald 1971) and to depict the source of illumination on the left (Sun \& Perona 1998). 
thought based on experience, the former response would seem to be the only plausible one.

So there are cases, common enough, where reference is fixed by the singling-out act. These are cases where visual experience plays a role in fixing the reference of a thought rather than just being the prompt or cause for forming a thought. In such cases Snowdon's point should apply.

There are a number of other possible means or channels that might determine the reference of a demonstrative thought - and so there can be other difficult cases in which two (or more) means or channels are in conflict.

a) There are the other senses. (Notice, of course, that CF theorists are typically $\mathrm{CF}$ theorists about all of the senses, not just vision.)

And so there could be cases in which two different senses provide rival determinants of reference for a thought ${ }^{8}$. E.g. I might be visually aware of A and tactilely aware of B, but wrongly take what I am seeing and what I am touching to be the same item. If I then form a thought 'This is F' it can be quite unclear which item my thought refers to.

b) There is other people's testimony - e.g. I might be listening to someone speaking about an animal and think 'That is my rabbit'. And there is memory ${ }^{9}-$ I might attend to a conscious memory and think: 'That was my rabbit'.

Again: I could be listening to testimony about A whilst looking at what is in fact B, and wrongly take what I'm looking at to be the same thing as what is being talked about.

${ }^{8}$ Shoemaker 1968 considers this kind of problem case, though he is not concerned to adjudicate which item if any gets referred to in such cases. See also Siegel 2002.

${ }^{9}$ Though perhaps it is not so clear that in the memory case we would normally be employing a demonstrative element in thought, where this is something like a bare label or tag. When we recall an object previously encountered we would normally have some kind of richer concept of, or 'file' on, the object. Though we may not have an explicit name for the object, we would not be thinking of it using the mental equivalent of a mere re-usable label or pointer. 
I have no particular theory to offer as to how reference might be determined in these conflicted cases - or whether there is any referential fact of the matter.

(c) There are also 'complex' demonstratives involving a noun or noun-phrase; as in 'That rabbit is cute' or 'This shirt is dirty' etc. There is much disagreement on the role of such noun phrases in determining the reference of the demonstrative. There is a question as to whether complex demonstratives are singular terms whose meaning (in a context) is simply the referent, or whether they are really quantificational in something like the way definite descriptions are held to be quantificational. And even assuming that complex demonstratives are still singular terms, there is then the question of what the role of the noun phrase is does its meaning restrict the possible reference of the complex demonstrative? Is the meaning of the noun phrase part of the content of the overall proposition? I don't want to wade in to these controversies here $^{10}$.

Complex demonstratives also raise the prospect of conflicting determinants of reference. E.g. I am looking at a brilliant portrait of the rabbit that I mistake for the real rabbit. I direct attention at the portrait and think 'That rabbit is furry'. Here I presumably intend to refer to the item in my visual field I am directing attention at, but I also intend to refer to a rabbit - I wrongly believe these are intentions to refer to the same one item ${ }^{11}$.

To repeat: I take the Snowdon-style point to unproblematically apply only to cases where the subject is clearly demonstrating via her visual awareness, rather than via some other channel or using a preexistent concept. And I think that such cases will still be plentifully common in everyday situations. E.g. when a subject fixes attention on an element in her visual awareness and simply wonders: 'What's that?' Here there are no referential intentions to pick out something of a certain kind or something one has previously encountered or

${ }^{10}$ Larson \& Segal 1995, Salmon 2002 and Richard 1993 all treat complex demonstratives as singular terms, though they differ over the role played by the noun phrase. Neale 2004 treats complex demonstratives as quantificational.

11 This is, I take it, what is going on in Donnellan's 1966 well-known examples illustrating 'referential', as opposed to 'attributive', uses of definite descriptions. 
referred to and there is no question of the other senses complicating matters.

A final point I should make explicit is that I have been concerned with demonstrative thought rather than public language utterances, and with mental singling-out acts rather than with the sorts of overt, external factors that might be determinants of reference for publicly uttered demonstratives - e.g. physical finger pointing. Thus, some of the sorts of contextual factors that might be invoked as relevant to the reference of publicly uttered demonstratives are not relevant to the case of demonstrative thoughts with which I am concerned. E.g. Wettstein 1984 argues, very roughly, that the referent of a public 'that...' utterance, is what a competent listener would take the speaker to be referring to given the context. So it may be that my publicly uttered claim: 'that is a rabbit', where I am completely fooled by a brilliantly life-like replica of my rabbit, could yet succeed in referring to the real rabbit rather then the replica I'm looking at. For perhaps a competent audience, given the context, would take my utterance to refer to the real rabbit. And perhaps the audience would arrive at this interpretation even if the audience knew of my mistaken belief that the replica I was looking at was the real rabbit. Nevertheless, were I to fix attention on the replica in my visual field and simply think: 'that is a rabbit', where I am fooled by the replica, my thought must refer to the replica, not the rabbit. In the case of thought, we cannot invoke an imaginary audience to overrule or overlook my mistake. The interpretation an imaginary audience would give to my demonstrative thought (supposing this even makes sense) is surely irrelevant, for we are considering what $I$ am thinking of, not what anyone else might interpret my judgement to be about.

\section{Some Possible Responses}

Let me briefly recap the problematic issue for CF theories:

If what visual consciousness provides is some common factor distinct from anything environmental then one needs to grasp this fact if demonstrative reference to the environment via visual experience is to succeed. But it is typically accepted that CF theories are revisionary with respect to pre-philosophical views. That is to say, most nonphilosophers do not hold that the visual field is (always) comprised of non-environmental features. So most people would be making very 
widespread referential errors in their demonstrative thoughts. Vast swathes of humanity would be failing to refer to the world via attending to elements in their visual fields. And this might well seem a rather unattractive commitment for a theory to have.

The precise range of demonstrative judgements that would then turn out false will depend on the range of properties that the CF theorist allows both the common factor and environmental items to possess. E.g. if both sense-data and roses are allowed to be red, then a thought such as 'That is red' might turn out to be true despite the fact that the subject fails to realise she is mentally singling out a red sensedatum and not a red rose. But if you think that roses are red but sense-data can only be red*, some distinct inner property of experience caused by environmental redness, then the subject's thought is bound to be false. But whatever the exact range of potentially shared properties, it looks like the CF theorist will end up being committed to attributing quite widespread falsity of demonstrative thoughts as a result of the widespread referential mistakes. Again, an unattractive consequence for a theory to have.

Note: Evans 1982 argues $^{12}$ that failing to realise one's visual experience is an hallucination would mean that a demonstrative formed on the basis of this experience would not refer to anything at all - one would have formed a 'pseudo-thought'. Conflating a mental and a physical feature would then be different to conflating two physical items - rather than referring to the wrong item, one would have failed to refer entirely. But this is clearly no help to the CF theorist; it is just as unattractive a consequence that people's demonstratives frequently fail to refer as that they frequently mis-refer.

Faced with this alleged consequence of their theory, the CF theorists might, it seems to me, respond in one of four ways:

(i) They could just accept that it is indeed a consequence that any subjects who do not understand their experiential situation will generally be failing to refer to the environment. Compare: Hume thought that the common man mistakenly attributes a property of their visual experience, colour, to environmental objects that do not possess such a property. But he thought that (as with our mistaken views on morality and causation) such conflation was practically harmless, or even served some pur-

${ }^{12}$ See also Dickie 2010. 
pose. So the idea would be that whilst a wide range of everyday demonstrative thoughts are strictly speaking either false or fail to refer entirely, they are nonetheless a useful or at least harmless means by which we can guide our behaviour and actions in the world. I think it is fair to say that, dialectically speaking, one would need very compelling philosophical arguments - e.g. from illusion or hallucination - before one was happy to swallow such a picture of widespread referential error or failure.

(ii) The CF theorists might want to deny that the natural prephilosophical position is one in which people fail to grasp their indirect experiential position. They would claim instead that non-philosophers in general would acknowledge, if asked, that the elements making up their visual field are always distinct from any elements in the environment. Although I don't personally find this plausible, I think it is perhaps the CF theorist's best option. Firstly, I suppose it is ultimately an empirical question what people would or would not generally acknowledge about the nature of their visual experiences. Secondly, the CF theorist might point to the prevalence of Cartesian-scepticalstyle scenarios in popular culture -e.g. 'The Matrix' etc - as evidence that the general population would be prepared to acknowledge that what their visual awareness delivers are elements distinct from anything in the physical environment. Thirdly, there is also perhaps anthropological and psychological evidence that humans are natural Cartesians, innately disposed to conceive of a mental realm distinct from the physical realm ${ }^{13}$.

Having said all that, I do not think this second response is convincing. Whilst the notion of hallucination - elements in the visual field that are not environmental - is no doubt part of most people's natural understanding of how experience could potentially be, the idea that all experience (normal perceptual experience) similarly involves the visual presentation of entirely non-environmental features is not, I suggest, something that people would naturally acknowledge, the popularity of 'The Matrix' notwithstanding. If the CF position were

${ }^{13}$ See Boyer (2003) for anthropological evidence that belief in disembodied spirits is universal. See Kuhlmeier et al (2004) for evidence from developmental psychology that children are born dualists as they do not expect people to be subject to physical laws. 
the natural view, one might wonder why so many philosophers have felt it worthwhile to provide arguments from hallucination and illusion, in the apparent belief that they are showing something novel and surprising. (Admittedly, it is hardly unknown for philosophers to provide elaborate arguments in support of uncontroversial theses...)

Notice that I am not claiming that non-philosophers do generally hold a determinate direct-relational view of the metaphysics of experience. Indeed I am not sure it even makes sense to speak of people having any set 'pre-philosophical' opinion on a philosophical question. (For this reason I dislike the label 'naïve realism'.) I am only claiming that the general population does not typically hold a determinately CF view of experience. This is, of course, ultimately an empirical claim for which I offer no evidence. Still, it strikes me as very plausible and it is something that $\mathrm{CF}$ theorists have also traditionally been happy to accept.

I think that cognitively unsophisticated creatures are relevant here. It seems plausible that young children and perhaps various animals are able to entertain simple demonstrative thoughts about the world on the basis of their visual experience - they can wonder: 'What's that?' But they lack any concept of 'inner' visual experience distinct from the (apparently) worldly objects of visual awareness - so they could not grasp the CF nature of experience. Attributing widespread referential failures to children is also quite a revisionary and, prima facie, unattractive consequence for a theory.

(iii) The everyday examples I provided in section 2 to illustrate Snowdon's point involved the subject conflating two environmental features. But a CF theorist might think that failing to acknowledge a mental or sensory intermediary is somehow different to the parallel mistake involving two normal, environmental objects. What goes for the environmental cases, they might argue, need not hold when, say, sense-data or experiential representations are involved. Even if one is mistaking a common-factor for some distinct environmental feature, an act of singling out the sensory item from the sensory array might still, somehow, allow for successful reference to the environmental item.

One of the few theorists I have encountered who explicitly considers the issue of demonstrative reference via experience is Barry Maund 
2003, who endorses this third line of thought. Maund states explicitly that:

'the naïve perceiver takes it that there is only one item there... The truth of the matter, however... is that there are two items... [and] the perceiver conflates the two.' (Maund 2003: 84)

Nonetheless, Maund wants to maintain that:

'perceptual experiences allow us [even the naïve] to have demonstrative thoughts about such [environmental] objects as cups.' (Maund 2003: 84)

Maund, in the spirit of Hume, insists that the 'conflation of [sensory] sign and thing signified... far from being damaging, or even harmless, is in fact beneficial' (Maund 2003: 85). Why might the naïve confusion of environmental object and mental/sensory feature be less ruinous to demonstrative thought than conflating two environmental items? Maund provides two reasons why conscious awareness of environmental objects via sensory intermediaries allows us to demonstratively refer to the environment even if we fail to grasp the indirect nature of our situation.

(1) The experience allows for successful behavioural targeting of the physical object.

(2) The experience is caused (in the right way) by the physical object.

This is not a strong argument. Neither of these factors provides any reason why we should treat the case of conflating a sensory intermediary with some environmental item any differently to a case in which two environmental items are conflated. Both of the factors Maund mentions - enabling successful targeting behaviour and causal connections of the right kind - might equally be present with a physical intermediary.

Consider 'successful behavioural targeting' first: E.g. A cleverly located hologram of a cup may allow me to target my behaviour successfully at the actual cup - by placing the hologram in front of the actual cup I may walk in the right direction, be able to inform others of the actual cup's location, reach towards it etc. None the less it should be clear that, despite such successful behaviour towards the actual cup, if I fail to grasp that what I am visually aware of is really a 
hologram rather than the cup itself then when I single out the hologram in visual field, my thought: 'That is made of bone china' will be false. Successful behaviour notwithstanding, I am mistaking a hologram for a cup; my demonstrative is, unbeknownst to me, actually latching onto something that is neither a cup nor made of china. If I were to think a thought like 'That is on the table', where the hologram is in fact on the table, then my thought would, fortuitously, be true, but my demonstrative would still be referring, unbeknownst to me, to the hologram I have singled out in my visual field and not to any cup.

And we could certainly build into the hologram example that the hologram is causally sensitive to the state of the actual cup and covaries with it to just the same degree as the proposed co-variance of sense-data and cup. The existence of causal links between a proximal intermediary and a distal object are simply irrelevant. If I have mistaken what it is that has been singled out - I have mistaken an entity distinct from the cup, for the cup itself - then demonstrative reference via that singling out will not refer to what I expect.

Since the two conditions Maund adduces make no difference when the subject is conflating two environmental items, we have no reason to think they should make any difference when the conflation involves a sensory item. Conflating a sense-datum, or qualia, or a mental representation with an environmental feature is still a conflation. Until some better argument than Maund's is provided, we should continue to conclude that $\mathrm{CF}$ theorists are committed to attributing a widespread failure to refer to the environment to those who do not accept their theory ${ }^{14}$.

(iv) Finally, the $\mathrm{CF}$ theorist might seek to deny some part of the 'natural story'. I take it this would also be an unintuitive cost for the CF theorist, who would then need an alternative story as to how experience and attention are involved in fixing the reference of demonstrative thoughts. (Or perhaps a story as to why there is really no such thing as demonstrative thought.)

\footnotetext{
14 To be clear: I have not provided an argument ruling out even the possibility that a CF theorist might provide some reason, different to Maund's, why the failure to grasp the presence of a mental intermediary is crucially different to cases where the subject fails to grasp that she is aware of a environmental intermediary. All I have shown is that we have no reason so far to treat these two kinds of cases differently.
} 


\section{Some Final Remarks}

Before making some final remarks it is worth emphasising: I have not been trying to provide any sort of knock-down refutation of common-factor theories. I have merely sought to highlight what is apparently an unintuitive and revisionary consequence of such theories, one that seems not to have received much mention.

Some philosophers (e.g. Austin 1962: 15-19) have complained that the distinction between direct and indirect awareness is ill-defined or unhelpful. Snowdon's paper was meant to clarify this distinction by invoking demonstrative reference. I have illustrated Snowdon's point by appealing to everyday cases in which it seems quite clear that we have visual awareness of $O$ only in virtue of really/directly seeing something else - seeing O's shadow, seeing O's photograph. However, there remains a range of problematic cases in which it can seem quite unclear where we want to draw the line between seeing directly or indirectly. E.g. seeing $O$ through spectacles, seeing $O$ through a magnifying glass, through binoculars, through a telescope, through a periscope, through left-right inverting goggles, through 'night-vision' goggles, via a digital movie camera in 'real time', via a digital movie camera with a 1-hour delay . . .

Snowdon's point does not, by itself, help to decide such problem cases one way or the other, for it does not tell us how to decide whether something is a 'transparent' or 'invisible' medium through which we gain awareness of $\mathrm{O}$ itself, or whether it constitutes a distinct visible intermediary ${ }^{15}$. For instance, if we accept that there is such a visible entity in the

${ }^{15}$ When M is totally or perfectly transparent then it is simply invisible/unsensible. It is just not possible for the subject to have visual awareness of $M$ at all, and so nor could the subject discriminate $M$ from its surroundings, nor fix attention on $\mathrm{M}$ as an element in the visual field and mentally "point" to it. When $\mathrm{M}$ is only imperfectly transparent, like a slightly dirty pane of glass, then $\mathrm{M}$ is potentially visible and so it would be possible to perform two different attentional acts - one could attend to $\mathrm{O}$ (through $\mathrm{M}$ ) or to $\mathrm{M}$ (itself). But when $M$ is an intervening entity/medium then there is not the possibility of two distinct acts of attention within visual experience - the only way to (indirectly) attend to O just is to (directly) attend to $\mathrm{M}$. 
visual field as a mirror image of $\mathrm{O}$, something distinct from $\mathrm{O}$, then seeing $\mathrm{O}$ in a mirror is seeing it indirectly. Whereas if we think there is no such genuinely distinct entity as an image, then seeing $\mathrm{O}$ in a mirror is just an unusual way of seeing (directly) $\mathrm{O}$ itself, like seeing $\mathrm{O}$ through clear glass or through thin air. (The mirror would then provide a way of 'transparently' looking at $\mathrm{O}$ itself, rather than showing a distinct image of O.) I have offered no general method for deciding whether something is just a transparent medium or constitutes an opaque intermediary.

Still, an obvious and compelling reason for thinking that one has visual awareness of an intermediary, rather than $\mathrm{O}$ itself, would be if one's visual field could remain essentially unchanged despite $\mathrm{O}$ changing or vanishing. Which is, of course, just the scenario envisaged in arguments from hallucination. On this basis, any theorist who accepts that there is conscious awareness of a common-factor in both a perception of $\mathrm{O}$ and an indistinguishable non-perceptual case would appear to be committed to the presence of an intermediary, distinct from $\mathrm{O}$, in the visual field. In other words, any phenomenological common-factor theory will involve awareness of an intermediary distinct from $\mathrm{O}$, and so Snowdon's point would apply.

Intentional theorists are typically common-factor theorists, indeed this is considered a main virtue of the theory. But they also typically conceive of themselves as direct theorists. McGinn is explicit on this point:

'My view is that we see objects 'directly' by representing them in visual experience.' (McGinn 1983: 129)

Barry Maund goes so far as to claim that direct-ness is a commitment of all intentional theories:

'...theorists who admit the role of representations... are all agreed that the theory is a form of direct realism: representational states are involved in perception but neither they, nor components of them, are said to be 'objects' for the perceiver, nor objects that constitute a veil between perceiver and the world.' (Maund 2003: 7-8) 
However, Maund surely goes too far in claiming that all intentionalist theorists are agreed on the direct status of such theories. For example, Tim Crane, himself a prominent intentionalist, is equally explicit in his repudiation of this direct status:

'...critics of intentionalism are right when they say that on the intentionalist view, perception 'falls short' of the world, and in this sense creates what Putnam calls an 'interface' between the mind and the world. The essence of perception - perceptual experience itself - does fall short of the world. But, according to the intentionalist, this is not something which should create any epistemological or metaphysical anxiety; it is simply a consequence of a general aspect of intentionality as traditionally conceived.' (Crane 2006: 141)

I happen to think that Crane is quite right to concede that intentionalism is an indirect view, but nothing essential to my argument turns on the meaning of the terms 'direct' or 'indirect' as applied to theories of conscious experience. I hope this paper will have raised a referential anxiety for any intentionalist who accepts that experiences are essentially such that they can be common factors. A common factor must, ex hypothesi, be something distinct from anything environmental; and so the possibility opens up of mistaking this non-environmental feature for something environmental. This would presumably be a mistake committed frequently by any of us who have not yet accepted that the elements comprising the visual field are nonenvironmental elements, elements common to perceptions and hallucinations. If the argument of this paper has been correct, the referential difficulties that would result from such a mistake are not only an issue for avowedly indirect sense-data theories, but for any common-factor theory ${ }^{16}$.

${ }^{16}$ This paper was presented at the $13^{\text {th }}$ T.I.F. conference in Barcelona, 2011. I am very grateful to Giovanni Merlo for his insightful reply on that occasion. Ancestral versions of this paper were presented to audiences at the 2008 London Graduate Conference, Cornell University and King's College London. I would also like to thank: Karen Bennett, Alex Davies, Gabriel Lakeman, Michael O’Sullivan, Stephen Raleigh, Gabriel Segal, Paul Snowdon, Charles Travis and Sasha Vereker for their comments. 

Instituto de Investigaciones Filosóficas, U.N.A.M.

Ciudad Universitaria, 04510, Coyoacán

México, D.F. traleigh@gmail.com

\section{References}

Austin, John L. 1962. Sense and Sensibilia. Oxford: Oxford University Press.

Bermúdez, Jose L. 2000. Naturalized Sense-Data. Philosophy and Phenomenal Research 61: 353-374

Bowers, Dane \& Heilman, Kenneth M. 1980. Pseudoneglect: Effects of hemispace on a tactile line bisection task. Neuropsychologia 18: 491-498.

Boyer, Pascal. 2003. Religious thought and behaviour as by-products of brain function. Trends in Cognitive Science 7(3): 119 - 124

Campbell, John. 2002. Reference and Consciousness. Oxford: Clarendon Press.

Campbell, John. 2006. Sortals and the Binding Problem. In Identity and Modality, ed. by MacBride, Fraser. Oxford: Oxford University Press.

Crane, Tim. 2006. Is There a Perceptual Relation? In Perceptual Experience, ed. by Gendler, Tamar. \& Hawthorne, John. Oxford: Oxford University Press.

Dean, Alexander. 1946. Fundamentals of play directing. New York.

Dickie, Imogen. 2010. We are Acquainted with Ordinary Things. In New Essays on Singular Thought, ed. by Jeshion, Robin. Oxford: Oxford University Press.

Donnellan, Keith S. 1966. Reference and Definite Descriptions, Philosophical Review 77: 281-304.

Evans, Gareth. 1982. The Varieties of Reference. Oxford: Clarendon Press.

Jeshion, Robin. 2010. Introduction to New Essays on Singular Thought. In New Essays on Singular Thought, ed. by Jeshion, Robin. Oxford: Oxford University Press.

Kuhlmeier, Valerie, Wynn, Karen \& Bloom, Paul. 2004. Do 5-Month-Old Infants See Humans as Material Objects? Cognition 94: 95-103.

Larson, Richard \& Segal, Gabriel. 1995. Knowledge of Meaning. Cambridge, MA: MIT Press.

Maund, Barry. 2003. Perception. Acumen Publishing

Neale, Stephen. 2004. This, That, and the Other. In Descriptions and Beyond, ed. by Reimer, Marga \& Bezuidenhout, Anne. New York: Oxford University Press.

Nelson, Thomas \& MacDonald, Gregory. 1971. Lateral organization, perceived depth and title preference in pictures. Perceptual and Motor Skills 33: 983-986.

Pylyshyn, Zenon. 2003. Seeing and Visualising. Cambridge MA: MIT Press. 
Pylyshyn, Zenon. 2007. Things and Places: How the Mind Connects with the World. Cambridge MA: MIT Press.

Richard, Mark. 1993. Articulated Terms. Philosophical Perspectives 7: 207-230.

Salmon, Nathan. 2002. Demonstrating and Necessity. Philosophical Review 111: 497537.

Shoemaker, Sidney. 1968. Self-Reference and Self-Awareness. Journal of Philosophy 65: 555-67.

Siegel, Susanna. 2002. .The Role of Perception in Demonstrative Reference. Philosophers' Imprint 2 (1) (www.philosophersimprint.org/002001).

Smithies, Declan. Forthcoming. What is the Role of Consciousness in Demonstrative Thought? Journal of Philosophy, forthcoming.

Snowdon, Paul. 1992. How to Interpret 'Direct Perception'. In The Contents of Experience, ed. by Crane, Tim. Cambridge: Cambridge University Press.

Sun, Jennifer \& Perona, Pietro. 1998. Where is the sun? Nature Neuroscience 1: 183184.

Turnbull, Oliver \& McGeorge, Peter. 1998. Lateral bumping: A normal-subject analog to the behaviour of patients with hemispatial neglect? Brain and Cognition 37: 31-33.

Tye, Michael. 2009. Consciousness Revisited. Cambridge MA: MIT press

Wettstein, Howard. 1984. How to Bridge the Gap Between Meaning and Reference. Synthese 58: 63-84. 